\title{
A morphometric study of the sella turcica: race, age, and gender effect
}

\author{
F.K. Muhammed ${ }^{1}$, A.O. Abdullah' ${ }^{2}$, Y. Liu ${ }^{1}$ \\ 'Department of Orthodontics, School and Hospital of Stomatology, China Medical University, \\ Liaoning Provincial Key Laboratory of Oral Diseases, Shenyang, P.R. China \\ ${ }^{2} S c h o o l$ and Hospital of Stomatology, China Medical University, Liaoning Provincial Key Laboratory \\ of Oral Diseases, Shenyang, P.R. China
}

[Received: 3 July 2019; Accepted: 2 August 2019]

Background: The aim of this study was to evaluate the morphological appearance, bridging incidence, and linear dimensions of sella turcica (ST) in Chinese and Nepalese individuals.

Materials and methods: This retrospective study examined digital standardised lateral cephalometric of 360 Chinese and Nepalese subjects, which consisted of 116 females and 64 males with an age range of 8-28 years. The sella morphology, bridging, and size were assessed on the lateral cephalometric radiographs, and the data were correlated with race, gender, and age.

Results: Sella turcica presented a normal morphology in most Nepalese (90\%) subjects whereas flat-shaped morphology were highly prevalent among Chinese subjects (36. 7\%). The frequency of full bridging was 2.8\% and $11.7 \%$ for Chinese and Nepalese subjects, respectively. When the race was compared with sella size, a statistically significant difference was detected in length $(p<0.05)$ and diameter ( $p<0.001$ ) of ST. A significant correlation was found between length and diameter of the ST and age in Chinese and Nepalese subjects. No significant correlation was observed between the size of ST and gender of Chinese and Nepalese subjects. The only parameter significantly associated with race, age and gender was the diameter of ST.

Conclusions: These findings assist orthodontists, neurosurgeons, and forensic medical investigators to focus on the diameter of ST during orthodontic treatment planning, diagnosis of pathology of the pituitary gland, and age determination. (Folia Morphol 2020; 79, 2: 318-326)

Key words: sella turcica, lateral cephalometric, linear dimensions, China, Nepal

\section{INTRODUCTION}

Anatomical structures in lateral cephalometric images were determined as reference points during the measurement and positioning of the upper and lower jaws in relation to the cranial base. These landmarks act as vital diagnostic tools that aid the orthodontist during evaluation of the outcomes of orthodontic treatment $[1,22,35]$. The sella turcica (ST) is an essential saddle-shaped primitive structure found in lateral cephalometric image [33]. The sella point, which is situated in the centre of the ST [35], is one of the most widely applied cranial landmarks for cephalometric

Address for correspondence: Prof. Y. Liu, Department of Orthodontics, School and Hospital of Stomatology, China Medical University, Liaoning Provincial Key Laboratory of Oral Diseases, Nanjing North Street \#117, He-Ping District, Shenyang 110002, P.R. China, tel: +86 24 31973999 , fax: +024-31973999, e-mail: liuyi@cmu.edu.cn 
analysis [26]. The ST possesses anterior and posterior clinoid processes, and central hypophyseal fossa situated in the superior part of the sphenoid bone. In the cranial base the ST contains the pituitary gland $[1,25$, 28]. Various morphological alterations have been detected and many categorisations have been described $[3,26]$. On a lateral cephalometric radiograph, the ST has a diverse morphological structure, which has been categorised into round, oval, and flat [13]. The round and oval ST are the most prevailing forms [11]. The normal morphology of the ST ought to be identified to determine whether the sella region presents a remarkable appearance [1]. The shape of the ST was affected by various syndromes such as Trisomy 21, Meckel-Gruber syndrome, Turner syndrome [33], and Axenfeld-Rieger syndrome [23]. An altered ST morphology is present in patients with spina bifida [5], type I diabetic patients [33], congenital malformations [20], aneurysms, and Rathke's cleft cysts [22].

Various methods have been suggested to measure the size of the ST on lateral cephalometric radiographs [2]. The size of the ST has great concern under certain clinical circumstances. A larger size of the ST is associated with clinical problems and may be a manifestation of a mass lesion including a pituitary tumour leading to Cushing's syndrome, and acromegaly [32]. Empty ST was identified by enlarged sella with a double floor [33]. Small ST is notable in humans who either have a partially formed diaphragm sella or may represent a normal anatomic variation [26]. In contrast, unusual small ST implies to be unique and detected in Sheehan's syndrome and primary hypopituitarism [33].

The sella calcification (bridge) of the interclinoid ligament is an integrated bony structure found as a result of irregular expansion in the anterior, middle, and posterior clinoid processes [27]. An altered ST morphology or bridging of the sella is observed in subjects with severe craniofacial deviations. An alteration from the normal size and morphology of the ST can be an implication of a pathological condition of the pituitary gland [5], spina bifida $[5,17$, 19], dental anomalies [20], Hurler's syndrome [21] and other syndromes and disorders $[15-17,21]$ or is considered as a normal variant of the ST [20]. Different radiographic modalities have been used to measure the size and morphology of the ST [1, 34]. Numerous researchers have studied the morphology, bridging and size of the ST in the individuals in their own countries [1, 2, 10-12, 24, 34]. However, alterations in the ST dimensions among the Chinese and Nepalese individuals have not been studied previously. The current study was therefore set up to identify the morphological appearance, bridging incidence, and linear dimensions of the ST among Chinese and Nepalese patients. This study also identifies possible race, age, and gender correlation with ST size. The null hypothesis was that there was no association between the linear variations of the ST and race, age and gender group.

\section{MATERIALS AND METHODS}

The ethics approval for this retrospective study was provided by the Local Research Ethics Committee of Stomatology of China Medical University. All procedures followed were in accordance with the ethical standards of the responsible committee (institutional and national) and with the Helsinki declaration. Individuals from two different geographic locations were studied: Shenyang and Dhulikhel cities. Details of the data collection are summarised in Table 1 . The study group consisted of 180 subjects from each racial group, among whom 116 and 64 were female and male, respectively. The data were categorised into two age groups, 8-14 years and 15-28 years; these age groups correspond to pre and post-pubertal stages, respectively. The average age is shown in Table 2 . The selection criteria for these age-defined groups were according to the following multiple observations: (i) no significant alteration was observed in the morphology of the ST after 12 years of age [6], (ii) females completed their pubertal progress at roughly 15 years old [29], and (iii) roughly the same size of the ST were studied in young adult female and male, except during pregnancy $[1,11,24,34]$. Inclusion criteria: all subjects were clinically healthy, without major illnesses or medical conditions, and all class III patients were managed by orthodontics alone without surgical intervention. Subjects with craniofacial syndromes, trauma, cleft lip and palate, and those who have undergone multi-reagent chemotherapy and poor quality images were excluded [20]. The principal author reviewed and measured all cephalometric radiographs. Chinese records were retrieved from clinic visits. For the Nepalese subjects, electronic collection of digital lateral cephalograms with records was perfomred. Radiographs are now commonly used, and referrals, along with photographs, are being transferred via email $[8,9]$. The 
Table 1. Details of data collection and radiographic instrumentation

\begin{tabular}{lcc}
\hline Categories & Chinese & Nepalese \\
\hline City & Shenyang & Dhulikhel \\
Race & Chinese & Nepalese \\
Subjects $(\mathrm{n})$ & 180 & 180 \\
Data collection site & Department of Orthodontics, School of Stomatology, China Medical University & Private clinic \\
Radiograph system & Proline XC2009 & Vatech, Pax-i3D Smart ${ }^{\text {TM }}$ \\
kV & 64 to 68 & 50 to 90 \\
$\mathrm{~mA}$ & 5 to 6 & 4 to 16 \\
Exposure time $[\mathrm{s}]$ & 12.8 & 12.9 \\
\hline
\end{tabular}

Table 2. The mean age of study groups in female and male in each racial group

\begin{tabular}{lcccc}
\hline Gender & Age group [years] & N & Chinese & Nepalese \\
\cline { 4 - 5 } & & & Mean \pm SD & Mean \pm SD \\
\hline Female $(\text { total }=116)^{*}$ & $8-14$ & 62 & $11.6 \pm 1.784$ & $11.4 \pm 1.564$ \\
Male $(\text { total }=64)^{*}$ & $15-28$ & 54 & $17.6 \pm 2.612$ & $18.9 \pm 2.917$ \\
& $8-14$ & 24 & $11.4 \pm 2.041$ & $11.2 \pm 1.921$ \\
\hline
\end{tabular}

${ }^{*}$ Total number of subject in each racial group; $n$ — number of subjects in each age, gender and racial group. Age group of each racial group presented as mean \pm standard deviation (SD)

linear dimensions (length, depth and diameter) of the ST were measured using digitising Winceph ${ }^{\circledR}$ version 8.0 software (Rise Corporation, 29-33-301, Sakuragaokacho, Shibuyaku, Tokyo 150-0031, Japan) according to the procedure specified by Silverman [31]. Radiographic images were of proper quality and clearly exhibited the structure of the ST. The imaging analysis software was calibrated to account for any variations in magnification obtained from the radiograph and/or cephalostat. A bone filter was applied to improve contrast and obtain proper position of the structures.

Four ST landmark points were placed: 1 . The tuberculum sella (TS), which is the anterior point of the contour of the ST; 2 . The dorsum sella (DS), which is the posterior wall of the ST; 3 . The base of the pituitary fossa (BPF), which is the deepest point on the floor of the pituitary fossa; 4 . The anteroposterior diameter (APD), which is the furthest point on the posterior inner wall of the fossa. Figure 1 presents cephalometric landmarks that the software-calibrated linear measurements of sella length (a) as the line distance from TS to DS; depth (b) as a perpendicular line distance from the midline of the TS-DS to the

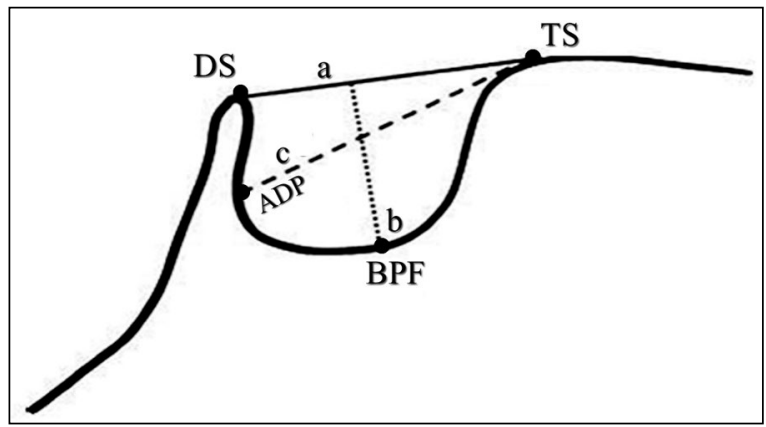

Figure 1. Normal sella turcica morphology: tuberculum sella (TS), dorsum sella (DS), base of the pituitary fossa (BPF); a - length of sella (black line); $b$ - depth of sella (dotted line); c — diameter of sella (dashed line).

BPF; and the diameter (c) of the ST as a line distance from the TS-ADP. Three types of the ST morphology was distinguished on radiographic: U-shaped, wherein the dorsum and tubercle of the ST are at the same height. J-shaped, wherein the dorsum sella is in a lower position in relation to the tubercle of the ST. Flat-shaped, when the depth of ST is minimal $[10,11$, 24]. ST bridging was categorized into no calcification (normal), partially calcified, and completely calcified 
based on previous studies [20, 24, 28]. Partially calcified ST was radiographically visible as an extension without fusing of the anterior and posterior clinoid process. The radiographs where fusions (ribbon-like fusions) of the anterior and posterior structures of the ST were radiographically visible were classified as full bridging. To reduce error as a result of intra-examiner variability, 20 lateral cephalometric images from each racial group were randomly opted and re-evaluated by the same investigator with 1-month time interval after the initial analysis. In this study, the intraclass correlation coefficient (ICC) was applied. The ICC estimates and their $95 \%$ confidence intervals $(\mathrm{Cl})$ were analysed with SPSS statistical package. The ICC is a commonly applied index of measurement reliability to evaluate the reproducibility of the readings [18].

\section{Statistical analyses}

One-way analysis of variance (ANOVA) test was used for comparing ST dimensions between racial groups. The Welch unequal variance t-test was applied to compare the mean differences in the ST measurements between the two age groups and between genders. Multiple linear regression models was adopted to evaluate the effects of race, age, and gender on the length, depth and diameter of the ST. Statistical software IBM SPSS Statistics 20.0 (IBM, New York, US) was performed for the statistical analysis of the data. The mean values and standard deviations were calculated for each parameter as descriptive statistics. Significance was set at the $p<0.05$ level.

\section{RESULTS}

The ICC measurements in ST length, depth and diameter for Chinese was (0.92, 0.96 and 0.99), and Nepalese (0.96, 0.92 and 0.92 ), respectively. The results exhibit excellent reproducibility of the re-measured radiographs. Based on the $95 \% \mathrm{Cl}$ of the ICC estimate, values greater than 0.90 are indicative of excellent reliability [18]. Three various morphologies of the ST were detected: U-, J-, and flat-shapes. The majority of Nepalese cases revealed a U-shaped morphology of the ST with the frequency of $90.0 \%$. Chinese subjects predominately had J-and flat-shaped ST ( $35 \%$ and $36.7 \%$, respectively). A small proportion of Nepalese $(1.7 \%)$ subjects had a flat-shaped morphology of the ST. The assessment of the ST bridging was categorised into three distinct types: Normal (no ST bridging), partially bridging, and ST bridging (STB). The incidence of no finding of STB in

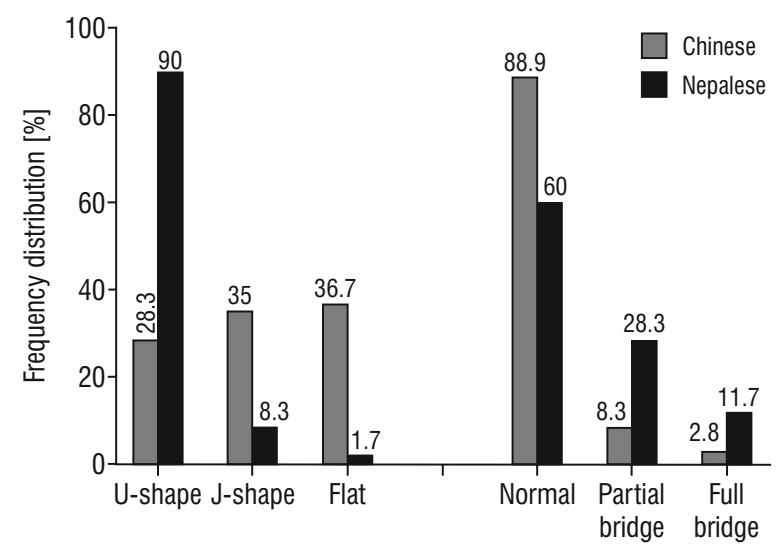

Figure 2. Frequency distribution of sella turcica bridging and shape by race.

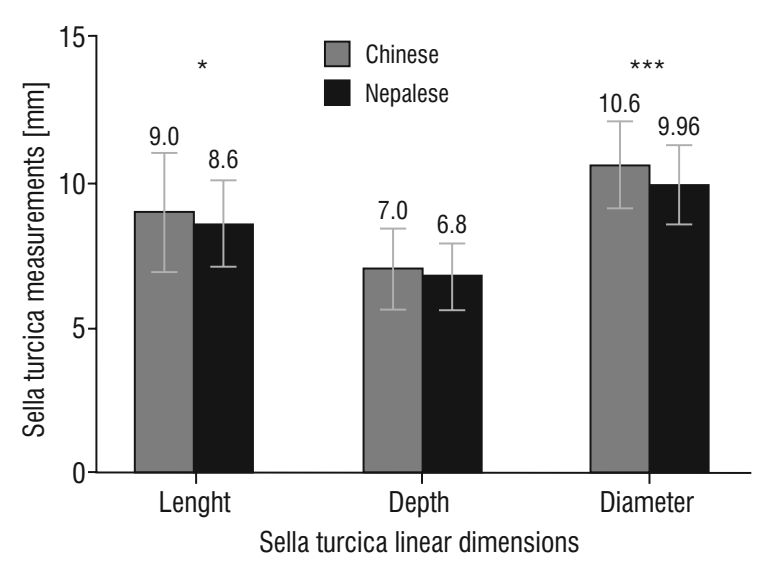

Figure 3. Effects of race on sella linear dimensions; ${ }^{*} p<0.05$; $* * * p<0.001$.

Chinese and Nepalese subjects was $88.9 \%$ and $60 \%$, respectively. The highest incidence of partial bridging was observed in Nepalese subjects at $28.3 \%$. STB occurred more frequently among Nepalese (11.7\%) subjects compared with the Chinese subjects (2.8\%) as presented in Figure 2 .

Figure 3 shows the outcomes of one-way ANOVA for the effects of race on sella length, depth, and diameter in Chinese and Nepalese subjects irrespective of age or gender. Results showed that differences in length $(p<0.05)$ and diameter $(p<0.001)$ of ST were significantly correlated with that of the two races. The ST length, depth and diameter by age group are presented in Table 3. The association between the size of the ST and age were statistically significant in the length and diameter in Chinese $(p<0.05$ and $p<0.01)$ and Nepalese patients $(p<0.01)$, respectively. Outcomes revealed that the Chinese and Nepa- 
Table 3. Linear dimensions of the sella turcica by age group

\begin{tabular}{|c|c|c|c|c|c|c|}
\hline Race & Age group [year] & $\mathbf{N}$ & Mean & SD & SEM & P\# \\
\hline \multicolumn{7}{|l|}{ Chinese } \\
\hline \multirow[t]{2}{*}{ Length } & $8-14$ & 86 & 8.6 & 1.985 & 0.214 & $0.033^{*}$ \\
\hline & $15-28$ & 94 & 9.3 & 2.090 & 0.216 & \\
\hline \multirow[t]{2}{*}{ Depth } & $8-14$ & 86 & 6.9 & 1.285 & 0.139 & 0.165 \\
\hline & $15-28$ & 94 & 7.2 & 1.463 & 0.151 & \\
\hline \multirow[t]{2}{*}{ Diameter } & 8-14 & 86 & 10.3 & 1.362 & 0.147 & $0.003^{* *}$ \\
\hline & $15-28$ & 94 & 10.9 & 1.539 & 0.159 & \\
\hline \multicolumn{7}{|l|}{ Nepalese } \\
\hline \multirow[t]{2}{*}{ Length } & $8-14$ & 86 & 8.30 & 1.390 & 0.150 & $0.005^{* *}$ \\
\hline & $15-28$ & 94 & 8.92 & 1.497 & 0.154 & \\
\hline \multirow[t]{2}{*}{ Depth } & $8-14$ & 86 & 6.75 & 1.082 & 0.117 & 0.464 \\
\hline & $15-28$ & 94 & 6.88 & 1.214 & 0.125 & \\
\hline \multirow[t]{2}{*}{ Diameter } & 8-14 & 86 & 10.24 & 1.356 & 0.146 & $0.008^{* *}$ \\
\hline & $15-28$ & 94 & 9.96 & 1.263 & 0.130 & \\
\hline
\end{tabular}

The p-value was shown correspond to comparisons made between age group for a single dimension of the same race. All measurements of the sella turcica are given in millimetres. "Statistical significance was assessed with Welch unequal variance t-test. ${ }^{*} \mathrm{p}<0.05$; ${ }^{* *} \mathrm{p}<0.01 ; \mathrm{N}$ - number of subjects; SD — standard deviation; SEM - standard error of the mean

Table 4. Linear dimensions of the sella turcica by gender

\begin{tabular}{|c|c|c|c|c|c|c|}
\hline & Gender & $\mathbf{N}$ & Mean & SD & SEM & $\mathbf{P}^{*}$ \\
\hline \multicolumn{7}{|l|}{ Chinese } \\
\hline \multirow[t]{2}{*}{ Length } & Female & 116 & 8.8 & 1.987 & 0.184 & 0.326 \\
\hline & Male & 64 & 9.2 & 2.189 & 0.273 & \\
\hline \multirow[t]{2}{*}{ Depth } & Female & 116 & 7.0 & 1.381 & 0.128 & 0.998 \\
\hline & Male & 64 & 7.0 & 1.400 & 0.175 & \\
\hline \multirow[t]{2}{*}{ Diameter } & Female & 116 & 10.7 & 1.516 & 0.140 & 0.195 \\
\hline & Male & 64 & 10.4 & 1.432 & 0.179 & \\
\hline \multicolumn{7}{|l|}{ Nepalese } \\
\hline \multirow[t]{2}{*}{ Length } & Female & 116 & 8.60 & 1.429 & 0.133 & 0.834 \\
\hline & Male & 64 & 8.65 & 1.566 & 0.196 & \\
\hline \multirow[t]{2}{*}{ Depth } & Female & 116 & 6.93 & 1.021 & 0.095 & 0.105 \\
\hline & Male & 64 & 6.61 & 1.340 & 0.168 & \\
\hline \multirow[t]{2}{*}{ Diameter } & Female & 116 & 10.09 & 1.362 & 0.126 & 0.075 \\
\hline & Male & 64 & 9.73 & 1.331 & 0.156 & \\
\hline
\end{tabular}

$\mathrm{n}$ - number of subjects. The $\mathrm{p}$-value was shown correspond to comparisons made between females and males for a single dimension of the same race. The dimensions of sella turcica measurement are provided in millimetres. *Statistical significance was assessed with Welch unequal variance t-test. $p>0.05$; SEM - standard error of the mean

lese subjects did not show any significant correlation between gender and the linear variables of the ST (Table 4).

To evaluate the associations between linear measures of the ST and race, adjusted for patients' age and gender, multiple linear regression models were performed. The results revealed that after the adjustment, the associations between diameter and all factors (race, age, and gender) were statistically significant. The length and depth were significantly associated with age (Table 5).

\section{DISCUSSION}

A cephalometric morphometric study of the ST has long been investigated previously [1, 2, 24, 34]. This retrospective study describes the morphological appearance, the incidence of bridging and linear dimensions of the ST in the Chinese and Nepalese 
Table 5. Multiple linear regression models showing associations between race and size of sella turcica, adjusted for gender and age

\begin{tabular}{lccc}
\hline & $\begin{array}{c}\text { Regression } \\
\text { coefficient (B) }\end{array}$ & $\begin{array}{c}\text { Standard error } \\
\text { of the mean }\end{array}$ & $\mathbf{P}$ \\
\hline Length $\left(\mathbf{r}^{2}=\mathbf{0 . 0 5 8}\right)$ & -0.381 & 0.185 & 0.040 \\
Race & 0.766 & 0.187 & $0.000^{* *}$ \\
Age & 0.066 & 0.195 & 0.737 \\
Gender & & & \\
Depth $\left(\mathbf{r}^{2}=\mathbf{0 . 0 2 4 )}\right.$ & -0.251 & 0.134 & 0.062 \\
Race & 0.269 & 0.135 & $0.048^{*}$ \\
Age & -0.201 & 0.141 & 0.156 \\
Gender & & & \\
Diameter $\left(\mathbf{r}^{2}=\mathbf{0 . 0 9 9 )}\right.$ & -0.683 & 0.147 & $0.000^{* *}$ \\
Race & 0.536 & 0.149 & $0.000^{* *}$ \\
Age & -0.414 & 0.156 & $0.008^{*}$ \\
Gender & & & \\
\hline${ }^{*}<0.01 ;{ }^{* *}<0.001$ & & & \\
& & &
\end{tabular}

subjects and identifies any possible race, age and gender group associated with a size of the ST. Radiographic diagnosis of the ST shape was chosen to match previous studies and classified into $\mathrm{U}_{-}, \mathrm{J}-$, and flat-shapes [1, 10, 11, 24, 30]. In accordance with the present results, previous studies have demonstrated that a greater frequency of a $\mathrm{U}$ - and J-shaped ST has been observed in patients $[10,11,30]$. However, $\mathrm{J}$ - and flat-shaped ST were predominantly prevalent in Chinese subjects with an incidence rate of $35 \%$ and $36.7 \%$, respectively. The frequency of the J-shaped ST in Chinese subjects was identical to those recorded in the literature [11]. Previous study reported that $\mathrm{J}$-shaped ST is frequently found in neurofibromatosis [26]. It appears that the flat-shaped ST was less expected to develop among Nepalese subjects in the current study and compared with previous studies $[10,11,24,30]$. The flat-type ST is reportedly the lowest recurrent $[3,24]$. The observational results in this study provide different interpretation of ST morphology under some clinical conditions since any deviation in the development of the pituitary gland may lead to a deviation in the shape of the ST [33]. The study of morphology of the ST is essential because it houses the pituitary gland upon which progress depends and has a close contact to various neural and vascular systems [26]. The establishment of normal standards aid in a more objective evaluation and as a source of additional diagnostic knowledge associated to several pathologies $[2,26]$. The current study shows a strong tendency toward increased frequency of partial bridge in Nepalese patients with no clinical manifestation. Partial bridging among the Peruvian population was seen in $13.6 \%$ of 417 lateral cephalometric plain film radiography [28], this level is markedly lower than in Nepalese (28.3\%) subjects and higher than that of Chinese subjects (8.3\%). The highest incidence of partial bridging was documented at $38.9 \%$ of Bosnians [24], 38.4\% of Texas [7], and $37.2 \%$ of Iraqi patients [24]. STB may also occur in a healthy population within a range of $1.75 \%$ to $22 \%$ when measured in anatomical and radiographic studies $[3,12,14,23,34]$. The lowest incidence of STB was detected in the Chinese population in comparison to Nepalese populations. The highest incidence of STB was at $34.17 \%$ in Anatolian subjects based on a total of 80 dry skulls [27]. STB was not observed in 166 Bangladeshi subjects [12]. The prevalence of STB was high in medically compromised subjects and subjects with tooth anomalies $[5,28]$. STB of $18.6 \%$ was detected in 177 individuals with severe craniofacial disorders; $13 \%$ of 62 Norwegian children within Williams syndrome [4]; and $7.3 \%$ and $16.7 \%$ of 150 Caucasian subjects who had experienced orthodontic and surgical-orthodontic treatments, respectively [13]. Various STB ranges were observed in skeletal classes I, II, and III subjects in $1.1 \%$ of 180 Saudi Arabian subjects and $23.3 \%$ of 90 Iranian subjects $[1,34]$. It has been stated that the early appearance of ST bridges during development should perceptive the clinicians to possible tooth deviations in life later [20]. However, the effect of STB on the pituitary gland is not well understood [5].

Significant differences were found between racial groups and the length and diameter of the ST (Fig. 3). To date, no evidence has been reported associating Chinese and Nepalese subjects with the linear variables of the ST. However, previous study indicated that length and depth were significantly associated among racial groups [24]. The results indicated that ST in older age was consistently greater than in younger ages. This finding is in agreement with previously reported results, which showed that a direct and significant correlation among the length, depth, and diameter of the ST by advanced age is present [1, 3 , $10,24]$. In Iranian subjects, diameter was significantly correlated with age [34]. The present study confirms previous findings and contributes additional evidence that suggests the growth of the individual can be 
Table 6. Comparison of sella turcica length, depth, and diameter of Chinese and Nepalese subjects with other countries

\begin{tabular}{|c|c|c|c|c|c|c|}
\hline Country & $\begin{array}{l}\text { Subjects } \\
\text { (n) }\end{array}$ & $\begin{array}{c}\text { Sella } \\
\text { Length [mm] }\end{array}$ & $\begin{array}{c}\text { Sella } \\
\text { Depth [mm] }\end{array}$ & $\begin{array}{c}\text { Sella } \\
\text { Diameter }[\mathrm{mm}]\end{array}$ & Instruments & References \\
\hline China* & 180 & 9.0 & 7.0 & 10.6 & $C$ & \\
\hline Nepal* & 180 & 8.6 & 6.8 & 9.96 & C & \\
\hline Bosnia and Herzegovina & 180 & 9.6 & 6.6 & 10.8 & C & [12] \\
\hline Iraq & 180 & 8.8 & 7.5 & 10.8 & C & [12] \\
\hline India & 180 & 8.8 & 7.1 & 10.9 & C & {$[16]$} \\
\hline Saudi Arabia & 180 & 11 & 9.1 & 13.9 & C & [35] \\
\hline Pakistan & 180 & 11.4 & 9.8 & 13.9 & C & [34] \\
\hline Greece & 184 & 7.1 & 6.6 & $x$ & C & [20] \\
\hline Malaysia & 183 & 8.46 & 7.44 & 10.79 & СТ & [34] \\
\hline Bangladesh & 166 & 8.63 & 8.42 & 9.9 & СТ & {$[10]$} \\
\hline Turkey & 118 & $x$ & 9.3 & 14.1 & C & [34] \\
\hline Brazil & 100 & 10.31 & 6.33 & $x$ & СT & [18] \\
\hline Nigeria & 100 & 12.59 & 8.94 & $x$ & C & [34] \\
\hline Iran & 90 & 9.04 & 8.03 & 13.02 & C & [15] \\
\hline Iraq & 71 & 8.46 & 7.44 & 10.79 & СT & [13] \\
\hline
\end{tabular}

${ }^{*}$ Current study; Instrument used for data collection: C — cephalometry; CT — computed tomography; X — no data available

assessed based on the size of the ST at different age periods. The evidence from this study suggests that the linear dimensions of ST can be used as the additional clues for age determination in forensic medical investigations. The correlation between the ST size and gender was tested. In Chinese and Nepalese subjects, the size of the ST showed no correlation with gender. The results of this study were consistent with those in previous studies on Indian [10], Saudi Arabian [1], Pakistani [10], Malaysian [10], Bangladeshi [12], Nigerian [10], Iranian [34] and Iraqi [11] subjects; a significant difference was not observed among various sexual orientations in relation to the linear variables of the ST. A study in Greece revealed that sella height was anteriorly larger in males than in females [2]. Length of ST was found to be significantly associated with gender in Bosnians and Iraqi subjects [24]. The results highlight an indication that in the majority of the population there is no relationship between gender and linear dimensions of the ST. This research extends our knowledge of gender that cannot be a clinical diagnostic feature to assist clinicians in the diagnosis and treatment plan. The diameter was generally seen as a factor strongly related to race, age, and gender when linear regression analysis test was applied. The results of the current study verify that ST diameter is more attributable to these factors than length and depth. Contrary to previous results length of ST was significantly related to race, age, and gender [24]. The findings of this study support previous studies reporting that age was significantly related to the change in the length and diameter when comparing various racial groups [24], and skeletal classifications with linear dimensions of the ST [35]. However, in a study conducted by Valizadeh et al. [34], the associations of age with the size of the ST were not statistically significant. Table 6 shows a comparison of the finding of the present study and the current global data for the size of the ST [1, 2, $10,11,12,24,30,34]$. The number of subjects (180) used for each race is in agreement with the results of other investigators $[1,10,24]$. The linear dimensions of the 180 subjects in each racial group are lower than that in the Saudi Arabian [1] and Pakistani [10] subjects and almost identical with the Indian subjects [10]. Turkish [10] and Iranian [34] subjects showed a larger depth and diameter compared with the present findings; the largest sella length was recorded in Nigerian subjects [10]. The present study provides additional evidence concerning linear dimensions of the ST that can be used to approximate the size of the pituitary gland among Chinese and Nepalese populations. This research could be used as a reference standard for future investigations on diseased patients within populations. Moreover, knowing the morphology, bridging, and linear dimensions of the 
ST is essential for neurosurgeons who make surgery on cranial base [22], and for the orthodontist to be familiar with various morphologies of the ST to discriminate normal from abnormal appearance $[1,17]$. It is suggested that the association of these factors could be investigated in future studies.

\section{CONCLUSIONS}

Within the limitation of this study, the following conclusions can be drawn. Chinese subjects showed a high incidence of J- and flat-shaped ST with less incidence of bridging. The correlation of gender and age to the size of the ST were identical among Chinese and Nepalese subjects. The diameter was found to be the only parameter significantly associated with race, gender and age, justifying rejection of the null hypothesis. These findings assist orthodontists, neurosurgeons, and forensic medical investigators to focus on the diameter of the ST during orthodontic treatment planning, diagnosis of pathology of the pituitary gland, and age determination.

\section{Acknowledgements}

This work was supported by Liaoning Province Nature Science fund project (20180550420).

\section{REFRENCESES}

1. Alkofide EA. The shape and size of the sella turcica in skeletal Class I, Class II, and Class III Saudi subjects. Eur J Orthod. 2007; 29(5): 457-463, doi: 10.1093/ejo/cjm049, indexed in Pubmed: 17693429.

2. Andredaki $M$, Koumantanou $A$, Dorotheou $D$, et al. A cephalometric morphometric study of the sella turcica. Eur J Orthod. 2007; 29(5): 449-456, doi: 10.1093/ejo/ cjm048, indexed in Pubmed: 17974535.

3. Axelsson S, Storhaug K, Kjaer I. Post-natal size and morphology of the sella turcica. Longitudinal cephalometric standards for Norwegians between 6 and 21 years of age. Eur J Orthod. 2004; 26(6): 597-604, doi: 10.1093/ ejo/26.6.597, indexed in Pubmed: 15650069.

4. Axelsson S, Storhaug K, Kjaer I. Post-natal size and morphology of the sella turcica in Williams syndrome. Eur J Orthod. 2004; 26(6): 613-621, doi: 10.1093/ejo/26.6.613, indexed in Pubmed: 15650071.

5. Becktor JP, Einersen S, Kjaer I. A sella turcica bridge in subjects with severe craniofacial deviations. Eur J Orthod. 2000; 22(1): 69-74, doi: 10.1093/ejo/22.1.69, indexed in Pubmed: 10721247.

6. Björk A. Cranial base development. Am J Orthod. 1955; 41(3): 198-225, doi: 10.1016/0002-9416(55)90005-1.

7. Cederberg RA, Benson BW, Nunn M, et al. Calcification of the interclinoid and petroclinoid ligaments of sella turcica: a radiographic study of the prevalence. Orthod Craniofac Res. 2003; 6(4): 227-232, doi: 10.1034/j.16000544.2003.00243.x, indexed in Pubmed: 14606526.
8. Chang ZC, Hu FC, Lai E, et al. Landmark identification errors on cone-beam computed tomography-derived cephalograms and conventional digital cephalograms. Am J Orthod Dentofacial Orthop. 2011; 140(6): e289-e297, doi: 10.1016/j.ajodo.2011.06.024, indexed in Pubmed: 22133963.

9. Damstra J, Huddleston Slater JJR, Fourie Z, et al. Reliability and the smallest detectable differences of lateral cephalometric measurements. Am J Orthod Dentofacial Orthop. 2010; 138(5): 546.e1-8; discussion 546, doi: 10.1016/j. ajodo.2010.05.013, indexed in Pubmed: 21055590.

10. Hasan H, Alam M, Yusof A, et al. Size and morphology of sella turcica in malay populations: a 3D CT study. J Hard Tissue Biol. 2016; 25(3): 313-320, doi: 10.2485/jhtb.25.313.

11. Hasan $H$, Alam M, Abdullah $Y$, et al. 3DCT morphometric analysis of sella turcica in iraqi population. J Hard Tissue Biol. 2016; 25(3): 227-232, doi: 10.2485/jhtb.25.227.

12. Islam $M$, Alam $M$, Yusof $A$, et al. 3D CT study of morphological shape and size of sella turcica in bangladeshi population. J Hard Tissue Biol. 2017; 26(1): 1-6, doi: 10.2485/jhtb.26.1.

13. Jones RM, Faqir A, Millett DT. Bridging and dimensions of sella turcica in subjects treated by surgical-orthodontic means or orthodontics only. Angle Orthod. 2005; 75(5): 714-718, doi: 10.1043/0003-3219(2005)75[714:BADOST]2.0.CO;2.

14. Kantor M, Norton L. Normal radiographic anatomy and common anomalies seen in cephalometric films. Am J Orthod Dentofac Orthoped. 1987; 91(5): 414-426, doi: 10.1016/0889-5406(87)90394-5.

15. Kjaer I, Becktor KB, Lisson J, et al. Face, palate, and craniofacial morphology in patients with a solitary median maxillary central incisor. Eur J Orthod. 2001; 23(1): 63-73, doi: 10.1093/ejo/23.1.63, indexed in Pubmed: 11296511.

16. Kjaer I, Fischer Hansen B, Reintoft I, et al. Pituitary gland and axial skeletal malformations in human fetuses with spina bifida. Eur J Pediatr Surg. 1999; 9(6): 354-358, doi: 10.1055/s-2008-1072282, indexed in Pubmed: 10661842.

17. Kjaer I, Wagner A, Madsen P, et al. The sella turcica in children with lumbosacral myelomeningocele. Eur J Orthod. 1998; 20(4): 443-448, doi: 10.1093/ejo/20.4.443, indexed in Pubmed: 9753826.

18. Koo TK, Li MY. A guideline of selecting and reporting intraclass correlation coefficients for reliability research. J Chiropr Med. 2016; 15(2): 155-163, doi: 10.1016/j. jcm.2016.02.012, indexed in Pubmed: 27330520.

19. Lee HS, Kim SH, Kim SO, et al. A new type of dental anomaly: molar-incisor malformation (MIM). Oral Surg Oral Med Oral Pathol Oral Radiol. 2014; 118(1): 101-109. e3, doi: 10.1016/j.00oo.2014.03.014, indexed in Pubmed: 24908600.

20. Leonardi R, Barbato E, Vichi M, et al. A sella turcica bridge in subjects with dental anomalies. Eur J Orthod. 2006; 28(6): 580-585, doi: 10.1093/ejo/cjl032, indexed in Pubmed: 16954179.

21. MacLeod SP, Macintyre DR. Bilateral hypoplasia of mandibular condyles in Hurler's syndrome. Oral Surg Oral Med Oral Pathol. 1993; 75(5): 659-660, doi: 10.1016/00304220(93)90244-x, indexed in Pubmed: 8488036.

22. Magat G, Ozcan Sener S. Morphometric analysis of the sella turcica in Turkish individuals with different dento- 
facial skeletal patterns. Folia Morphol. 2018; 77(3): 543-550, doi: 10.5603/FM.a2018.0022, indexed in Pubmed: 29500897.

23. Meyer-Marcotty P, Weisschuh N, Dressler P, et al. Morphology of the sella turcica in Axenfeld-Rieger syndrome with PITX2 mutation. J Oral Pathol Med. 2008; 37(8): 504-510, doi: 10.1111/j.1600-0714.2008.00650.x, indexed in Pubmed: 18331556.

24. Muhammed FK, Abdullah AO, Rashid ZJ, et al. Morphology, incidence of bridging, and dimensions of sella turcica in different racial groups. Oral Radiol. 2019; 35(2): 127-134, doi: 10.1007/s11282-018-0328-x, indexed in Pubmed: 30484186.

25. Norton N. Netter's head and neck anatomy for dentistry. 2nd ed. Elsevier Saunders, Philadelphia 2011.

26. Papagrigorakis MJ, Karamesinis KG, Daliouris KP, et al. Paleopathological findings in radiographs of ancient and modern Greek skulls. Skeletal Radiol. 2012; 41(12): 1605-1611, doi: 10.1007/s00256-012-1432-3, indexed in Pubmed: 22609968.

27. Peker T, Anil A, Gülekon N, et al. The incidence and types of sella and sphenopetrous bridges. Neurosurg Rev. 2006; 29(3): 219-223, doi: 10.1007/s10143-006-0018-8, indexed in Pubmed: 16528575.

28. Pérez I, Chávez A, Ponce D. Frequency of sella turcica bridge and clinoid enlargement in lateral cephalometric plain film radiography from peruvians. Int J Morphol. 2013; 31(2): 373-377, doi: 10.4067/s0717-95022013000200002.
29. Pisaneschi M, Kapoor G. Imaging the sella and parasellar region. Neuroimaging Clin N Am. 2005; 15(1): 203-219, doi: 10.1016/j.nic.2005.02.007, indexed in Pubmed: 15927868.

30. Ruiz C, Wafae N, Wafae G. Sella turcica morphometry using computed tomography. Eur J Anat. 2008; 12: 47-50.

31. Silverman F. Roentgen standards for size of the pituitary fossa from infancy through adolescence. Am J Roentgenol. 1957; 78(3): 45-60, indexed in Pubmed: 13458563.

32. Sugata T, Myoken Y, Tanaka S. Acromegaly identified in a patient with a complaint of malocclusion. Oral Surg Oral Med Oral Pathol Oral Radiol Endod. 1998; 85(1): 44-46, doi: 10.1016/s1079-2104(98)90396-1, indexed in Pubmed: 9474613.

33. Tekiner H, Acer N, Kelestimur F. Sella turcica: an anatomical, endocrinological, and historical perspective. Pituitary. 2015; 18(4): 575-578, doi: 10.1007/s11102-014-0609-2, indexed in Pubmed: 25307180.

34. Valizadeh S, Shahbeig S, Mohseni S, et al. Correlation of shape and size of sella turcica with the type of facial skeletal class in an iranian group. Iran J Radiol. 2015; 12(3): e16059, doi: 10.5812/iranjradiol.12(3)2015.16059, indexed in Pubmed: 26557271.

35. Yáñez-Vico RM, Rodríguez-Caballero A, Iglesias-Linares A, et al. Craniofacial characteristics in cri-du-chat syndrome. Oral Surg Oral Med Oral Pathol Oral Radiol Endod. 2010; 110(6): e38-e44, doi: 10.1016/j.tripleo.2010.08.021, indexed in Pubmed: 21112524. 